Review

\title{
Establishing a Program for Individuals at High Risk for Breast Cancer
}

\author{
Fernando Cadiz ${ }^{1,}$, , Henry M. Kuerer ${ }^{2}$, Julio Puga ${ }^{1}$, Jamile Camacho ${ }^{1}$, Eduardo Cunill ${ }^{1}$, and Banu Arun ${ }^{3}$ \\ 1. Department of Gynecology and Obstetrics, Breast Cancer Center, Clinica Alemana, Universidad del Desarrollo, Santiago, Chile. \\ 2. Department of Surgical Oncology, The University of Texas MD Anderson Cancer Center, Houston, Texas, USA. \\ 3. Clinical Cancer Genetics Service, The University of Texas MD Anderson Cancer Center, Houston, Texas, USA.
}

$\square$ Corresponding author: Fernando Cadiz, MD, Department of Gynecology and Obstetrics, Breast Cancer center, Clinica Alemana, Universidad del Desarrollo, Santiago, Chile. Phone: 56222101394 Fax: 56222101394 Email: fcadiz9@yahoo.com.

() Ivyspring International Publisher. This is an open-access article distributed under the terms of the Creative Commons License (http://creativecommons.org/ licenses/by-nc-nd/3.0/). Reproduction is permitted for personal, noncommercial use, provided that the article is in whole, unmodified, and properly cited.

Received: 2013.04.15; Accepted: 2013.05.23; Published: 2013.07.01

\begin{abstract}
Our need to create a program for individuals at high risk for breast cancer development led us to research the available data on such programs. In this paper, we summarize our findings and our thinking process as we developed our own program.

Breast cancer incidence is increasing worldwide. Even though there are known risk factors for breast cancer development, approximately $60 \%$ of patients with breast cancer have no known risk factor, although this situation will probably change with further research, especially in genetics. For patients with risk factors based on personal or family history, different models are available for assessing and quantifying risk. Assignment of risk levels permits tailored screening and risk reduction strategies. Potential benefits of specialized programs for women with high breast cancer risk include more cost -effective interventions as a result of patient stratification on the basis of risk; generation of valuable data to advance science; and differentiation of breast programs from other breast cancer units, which can result in increased revenue that can be directed to further improvements in patient care.

Guidelines for care of patients at high risk for breast cancer are available from various groups. However, running a high-risk breast program involves much more than applying a guideline. Each high-risk program needs to be designed by its institution with consideration of local resources and country legislation, especially related to genetic issues. Development of a successful high-risk program includes identifying strengths, weaknesses, opportunities, and threats; developing a promotion plan; choosing a risk assessment tool; defining "high risk"; and planning screening and risk reduction strategies for the specific population served by the program. The information in this article may be useful for other institutions considering creation of programs for patients with high breast cancer risk.
\end{abstract}

Key words: Breast cancer, genetic counseling, BRCA, preventive therapy, prophylactic surgery.

\section{Introduction}

Since 2000, Clinica Alemana, located in Santiago, Chile, has been treating patients with breast cancer using a multidisciplinary approach. In 2011, the clinic directors decided to establish a clinic for patients at high risk for breast cancer based on current evidence showing that high-risk individuals require different screening and risk reduction strategies from those deployed for the population at large. Fundamentally, the decision to establish a multidisciplinary program for individuals at high risk for breast cancer was mo- 
tivated by the strong belief that all breast cancer centers should offer tailored prevention, screening, and risk reduction strategies. In fact, in 2004, the American College of Surgeons added genetic counseling and testing as a supportive service to the Commission on Cancer Program Standards (1).

In designing the Clinica Alemana high-risk clinic, the clinic directors drew in part on the experience of The University of Texas MD Anderson Cancer Center. Clinica Alemana is a member of MD Anderson's Sister Institution Network, administered by MD Anderson's Global Academic Programs. MD Anderson established a clinic for individuals at high risk for cancer in the late 1990s. In 2006, MD Anderson moved to a decentralized model, in which genetic counseling and medical risk assessment, together with tailored screening and risk reduction strategies, are offered in the care centers where patients with different kinds of cancers are treated rather than in one central clinic. In 2006, MD Anderson's Clinical Cancer Genetics Program reported 1500 patients visits; in 2011, the program reported 3400 visits.

In this article, we summarize key factors that were considered in designing the Clinica Alemana clinic for high-risk individuals and outline factors that should be considered in the design of any clinic for individuals at high risk for breast cancer. The advice presented herein is based on review of the literature, the Clinica Alemana experience of establishing a high-risk clinic, and the MD Anderson experience of operating a high-risk clinic. This article may be useful for other institutions considering creation of a high-risk program.

\section{Rationale for Specialized Programs for Individuals at High Risk for Breast Can- cer}

Breast cancer is the most common cancer in the world, with an estimated incidence of 1.4 million cases per year (2).

In the United States, breast cancer accounts for $25 \%$ of cancers among women, and in 2011, approximately 230,480 new cases of invasive breast cancer and 57,650 cases of in situ carcinoma were diagnosed (3). The lifetime risk of breast cancer for an American woman is $12 \%$, or 1 in 8 women. Wrongly interpreted, this fact may lead to the assumption that every American woman is at "high risk" for breast cancer development. However, this is not the case: in fact, an individual woman's risk of breast cancer development over the next 10 years will never be greater than 1 in 25 (3).

Worldwide, breast cancer incidence is increasing in both developed and developing countries per- haps secondary to dietary and reproductive changes. There is also evidence that BRCA mutations are being detected more often worldwide; however, because of their low prevalence, they are not expected to contribute substantially to the total number of breast cancer cases (4-8).

It is now known that certain women are not "average" with respect to risk of breast cancer but rather have identifiable factors that modestly or greatly increase their risk. Screening strategies have been developed for the general population, but high-risk women need special screening, along with counseling regarding strategies for reducing the risk of breast cancer.

Studies have shown that breast cancer risk-reduction strategies have a higher impact in high-risk women than in the general population $(9,10)$. Thus, if we desire to optimally distribute resources to achieve the greatest reductions in breast-cancer related morbidity and mortality, special attention should be paid to high-risk women.

In Chile, to our knowledge, before establishment of the Clinica Alemana program, there was only one program for individuals at high risk for breast cancer opened in 2009.

\section{Potential Benefits of a High risk Program}

A high-risk program may promote awareness of the different risk levels among women. In addition, creation of a high-risk program may facilitate development of educational presentations and materials. Stratifying patients by risk level will allow screening and prevention programs based on personal risk, making such programs cost-effective (11-15). Finally, a high-risk program can help promote primary prevention measures for all patients, such as healthy lifestyle and diet.

At the level of the individual, a formal risk assessment may reassure the individual and aid her or him in taking the appropriate actions based on individual risk. Even though few patients carry a deleterious mutation, this group will benefit the most from risk reduction interventions.

From the perspective of science, a high-risk clinic will generate valuable data, providing the opportunity for research, publications, and alliances with academic institutions in areas such as genetics, screening, risk assessment, and prevention. Quantitative risk-assessment results have been used in prevention research and studies evaluating biomarkers of breast cancer risk (16-18). A perfect example of this type of contribution is studies that have shown the higher prevalence of BRCA mutations among patients with triple-negative breast cancer, which led to changes in guidelines regarding risk assessment and 
genetic testing for patients with this breast cancer subtype (19).

Finally, adding a high-risk program to a breast unit will differentiate that unit from others. The availability of expertise on evaluation and management of high-risk patients may attract more patients and thereby increase revenue for the institution that can then be utilized for further improvements in patient care.

\section{Defining the Goals of a High Risk Pro- gram}

A program for patients at high risk for breast cancer needs to be developed according to the current legislation and health care conditions in the country where the program will be located and local decisions regarding what is wanted or needed. Regardless of where the program is developed, it may be useful to consider the excellent list of goals outlined by MacDonald (20) (Table 1).

MacDonald notes, "The goals of a genetic service are to minimize cancer incidence, morbidity and mortality" (20). These are long-term goals. It is also important to establish short-term goals that can be achieved in the process of reducing morbidity and mortality. Probably the first measureable results from a high-risk program will be changes in screening frequency, types of imaging, frequency of imaging, number and types of prophylactic surgeries, and number of patients and types of chemoprevention prescriptions in the enrolled patients. Once a breast cancer risk reduction strategy is applied, a long time may pass before measurable results are seen, which is very different from the situation with other preventive interventions, such as those for hypertension or dyslipidemia.

Table I. Goals of a cancer genetics service (a).

- Identify individuals at high risk for cancer and genetic mutation carriage

- Stratify patients according to risk and tailor screening and management according to risk

- Promote a healthy lifestyle as a primary preventive intervention

- Provide genetic counseling regarding cancer risk

- Protect patient privacy and confidentiality

- Provide education about factors that confer a high risk of breast cancer to clinicians and the community

- Establish research collaborations

- Publish your actions and the results of your interventions

- Promote your initiative and encourage the development of new programs for patients at high risk

- Create a cost-effective breast program

a Based on the goals proposed by MacDonald (20).

\section{Developing the Program}

Analysis of Strengths, Weaknesses, Opportunities, and Threats

A SWOT (strength, weaknesses, opportunities, and threats) analysis is useful at the outset of program development. Results of the SWOT analysis made for the Clinica Alemana high-risk program are shown in Table 2. This type of analysis may allow physicians and institutions to develop a program in a way that takes advantage of strengths and opportunities and overcomes or avoids threats and weaknesses that will be encountered in different possible scenarios.

Published experiences in the establishment of high-risk programs can also teach us aspects that need to be considered, such as having a feedback system in place to alert clinic leadership about failures and changes needed to keep the program functioning and successful (21). The cultural and social background of the patients attending the clinic should be considered (22). Finally, even with ideal conditions, difficulties such as an overcrowded system, lack of adherence to treatment, need for continuous medical education, and genetic testing implications may be encountered (23).

\section{Develop a Promotion Plan}

Along with a promotional plan, a simple referral guide should be created for distribution to physicians. Ideally, the guide should be kept visible in the clinics that may refer patients. Patients with relatives diagnosed with breast cancer frequently overestimate their own risk and may be interested in having a formal risk assessment. A program of this nature should also be promoted in the community encouraging patients to ask their physician for a referral.

\section{Establish Institutional Support and Rela- tionships with Health Insurance Provid- ers}

For any high-risk program, institutional support will be needed in terms of financing and time to develop the program.

The program will need to be marketed along with other ongoing prevention programs. It can be introduced to the whole institution at educational events where a program director describes the essential need for and importance of the program, the program's short-and long-term goals and the plans for accomplishing them, the program's expected benefits, and referral criteria. Institutional staff should be encouraged to participate. A clinic director should meet individually with the groups that will refer most of the patients, such as internal medicine, gynecology, and surgery, to foster relationships and develop a 
feedback system to make these groups part of the program.

Table 2. Results of a strengths, weaknesses, opportunities, and threats (SWOT) analysis conducted as a first step in development of a clinic for individuals at high risk for breast cancer at Clinica Alemana Chile.

\begin{tabular}{l}
\hline Strengths \\
- Breast cancer is the main cancer treated in our clinic \\
- Multidisciplinary breast cancer team working since 2000, with \\
weekly meetings \\
- Highly trained radiologist with experience in breast magnetic \\
resonance imaging \\
- Availability of genetic counseling \\
- First breast cancer unit in Chile to show a series of patients un- \\
dergoing contralateral prophylactic mastectomy \\
- Institutional support \\
Weaknesses \\
- Physicians are unaware of other programs for individuals at high \\
risk for breast cancer \\
- There are no risk assessment models specially designed for Latin \\
populations \\
- Private system of health care with high costs for appointments, \\
examinations, and surgeries \\
Opportunities \\
- Expand breast health program \\
- Tailored screening and treatments for patients \\
- Advance science and advance understanding of breast cancer \\
- Create referral links with physicians from other areas \\
- Involve the community \\
Threats \\
- Implementation of a new program with unfamiliar processes for \\
patients and referring physicians \\
- Lack of national legislation in genetics and risk assessment \\
- Because program will be established in a private institution, pro- \\
gram will depend on referral of patients from other physicians \\
- Will be difficult to demonstrate benefits from our actions in a short \\
period of time
\end{tabular}

Having health insurance support may allow for access to a large number of patients. To get health insurance companies to cover the services provided in the high-risk program, it should be explained that an economic benefit is expected from promoting prevention, screening, chemoprevention, and prophylactic surgeries, allowing resources to be focused where they are needed the most. Promotion of prevention as a cornerstone of breast cancer care may result in a larger number of patients attending the clinic. In the long term, a clinic for patients at high risk for breast cancer should produce a reduction in breast-cancer-related morbidity and mortality, which may be an interesting issue for insurance companies and the institution $(24,25)$.

\section{Identify Staffing Needs and Physical Lo- cation}

The medical staff necessary and the location where patients will be seen should be decided on the basis of available resources and the current number of breast cancers treated per year. Development and adjustments of the program will be easier if the program starts small and grows gradually.

The staff should include genetic counselors, nurses, physicians, psychologists, social workers, secretaries, and a data manager. A medical director is needed to assist with development and monitor achievements and opportunities for improving the program.

In some high-risk programs, breast cancer screening and prevention services for high-risk individuals are offered in a centralized high-risk clinic located in a different area from the breast cancer unit. Other high-risk programs offer their services in the clinic where breast cancer patients are treated. In this arrangement, the high-risk team interacts with the oncology team, sharing examination rooms and clinics, allowing continuous feedback. In 2006, MD Anderson adopted a decentralized model for its clinical cancer genetics service, with genetic counseling services offered in the clinics where patients with that type of cancer are treated (e.g., gynecologic cancers, gastrointestinal cancers). Since then, the MD Anderson program has experienced tremendous growth in the number of patients treated and the interactions among medical staff. Adoption of the decentralized model has been described as a primary driver of this growth.

Probably both centralized and decentralized systems have strengths and weaknesses. Defining which is a better fit for an individual program may be crucial. The clinic will have patients at different risk levels such as those diagnosed with deleterious mutations creating a "genetic clinics" and other group of patients that have a higher risk based on "high risk breast lesions", personal or family history of cancer or a elevated risk assessment model score. That group may be the majority creating a "sporadic high risk clinic". Both groups do have a higher risk but the screening and risk reduction strategies may be different involving a multidisciplinary team. At the beginning the volume of patients may be small allowing to have all patients together but as the clinic grows a categorization based on risk level may be consider. Having a defined risk assessment model and strategies to treat $\mathrm{ADH} / \mathrm{ALH} / \mathrm{LCIS}$ will allow a better categorization and management of the clinic. 


\section{Establish General Clinic Procedures}

The duration of appointments may be longer than the usual for patients being treated for cancer $(20,21,24,25)$ as both the patient and any companion attending the clinic may have many questions. Having a good scheduler and being realistic about appointment duration is critical to allow each patient to be counseled appropriately without compromising the time allotted to other patients.

Specific patient information will be required, such as pathology reports and extensive family history data, including dates and causes of death. Such data may be collected through online data submission, a written questionnaire given to the patient prior to the appointment, or a PC tablet computer given to the patient in the waiting room. Because the personal data collected, such as data on genetic mutations, may have serious extramedical implications, confidentiality is essential. A flexible system should be created that allows collection of data during both the first appointment and follow-up visits.

A weekly conference should be established for discussing new patients, reviewing the results of risk assessment for these patients, and developing corresponding proposals for managing the patients risk. Referring physicians should be invited. At the beginning of each weekly conference, presentations related to high risk can be given, which will accomplish the task of continuing medical education. Such an initiative may encourage teamwork by keeping referring physicians informed and allowing the people in charge of the program to verify that data are being stored for future publications and monitoring of the results of actions taken.

\section{Selecting a Risk Assessment Model}

When one chooses a risk assessment model, it is important to consider that each model's assessment of risk is based on epidemiologic data from a specific population and that models yield different results when applied to other populations. There is no risk assessment model specifically designed for Hispanic populations. A high-risk program should select the model that best fits the population that it will serve. The Gail model, which once applied only to white patients, has been updated to apply to other races/ethnicities, making it more suitable for different populations (26).

Risk assessment models use personal and family data to estimate the risk of developing breast cancer or having a deleterious mutation. There are two general types of models, empirical and Mendelian, and it is important to understand how they perform and to whom and when they should be applied.

\section{Measuring Model Performance}

The performance of risk assessment models can be measured with the $\mathrm{C}$ statistic, which is the same as area under the curve. The $\mathrm{C}$ statistic expresses the ability to identify which particular individuals in a group have a condition predisposing to a higher risk. A C statistic value of 1 indicates perfect discrimination; a $C$ statistic value of 0.5 indicates no better than chance. The $\mathrm{C}$ statistic calculated for commonly used risk assessment models ranges from 0.55 to 0.68 $(27,28)$. This may seem disappointing, but it is important to remember that risk assessment models only complement clinical evaluation by quantifying the risk assessment.

Another measure used to describe the performance of risk assessment models is the calibration score, which is the ability to accurately predict breast cancer incidence. The calibration score compares the expected number of events to the observed number of events. If the model performs perfectly, the result is 1 ; a number lower than 1 means that the model underestimates risk, and a number higher than 1 indicates that the model overestimates risk.

\section{Types of Risk Assessment Models}

Empirical models use specific observational data that are applied to a logistic regression model to obtain a quantitative assessment of risk for breast cancer development in a defined period of time. Empirical models assess mutation carriage probability by using "tabular scoring systems" assigning values to certain variables, giving a quantitative score correlated with a threshold value for being a mutation carrier (29). The Gail model is an empirical model with reported calibration scores from 0.93 to $1.03(30,31)$ but $C$ statistic values from 0.47 to $0.63(32,33)$. This is an example of a good population assessment model with limitations in clinical practice.

Mendelian models are based on Mendelian rules of inheritance; they use observational data to estimate the allelic frequency and penetrance of the genes of interest, giving estimates of the probability of genetic mutation carriage and the probability of cancer development. Comparisons of the seven most commonly used Mendelian models showed that all of them had a $\mathrm{C}$ statistic near 0.8 ; the best result was seen for the BRCAPRO model, which had a $C$ statistic of 0.82 (34). If more information is added to the BRCAPRO model, its discrimination may improve (35).

Genetic risk prediction models estimate cancer risk and the probability of being a genetic mutation carrier regardless of the family structure and disease pattern. To assess risk, they rely on pedigree analysis, 
making assumptions about gene and allelic involvement and how that will affect risk. The assumptions made may affect the accuracy of the calculation (36).

There are no big differences in accuracy between different models used to predict the mutation carriage probability, only slight differences in sensitivity and specificity when the same model is applied to different populations or when different models are applied to the same population $(34,35,37,42)$. Analysis of frequently used risk assessment models for deleterious mutation in the United Kingdom showed C statistics ranging from 0.72 to 0.77 (43).

Threshold values used to indicate the need for genetic testing vary. In the United States and most of Europe, the threshold will be a $10 \%$ risk of being a genetic mutation carrier; in the United Kingdom, the cut-off is $20 \%$ (44). Different cut-off values have an impact on the sensitivity and specificity of risk assessment models.

\section{Defining the "High Risk Patient": Risk Factors and Risk Categories}

Breast cancer risk factors and their impact on breast cancer risk (45-89) are outlined in Table 3. Among breast cancer patients, $5-10 \%$ will have a germline mutation related to breast cancer, $15-20 \%$ will have a family history of breast cancer, and $60 \%$ will not have a known risk factor (90-92).

Table 3. Breast cancer risk factors.

Not Modifiable

Genetic mutation: 2-3\% absolute risk per year; relative risk (RR) 10-20 (46-52).

Early menarche: $4 \%$ increase in RR per year earlier than the median age at menarche (53).

Age over 60 years: $0.33 \%$ absolute risk per year; RR 10 compared to risk of a 30year-old patient (45).

Race/ethnicity (populations with known predisposition to be carriers of mutations that increase their risk of developing cancer).

Late menopause: 3\% increase in RR per year later than the median age at menopause (53).

Previous chest irradiation: Cumulative risk by age 55 years, $29.0 \%$ (95\% CI, 20.2-40.1\%); RR 5-20 (45,54).

Family history: One first-degree relative with postmenopausal breast cancer, RR 1.8; one first-degree relative with premenopausal breast cancer, RR 3.3; two first degree relatives with breast cancer, RR 3.6; one second-degree relative with breast cancer, RR 1.5; three or more relatives with breast cancer, RR up to $4(55,56)$.

Personal history of breast cancer: RR 1.7-4.5; if patient < 40 years old when cancer diagnosed, RR up to 8.0 (57).

Potentially Modifiable

Age at first birth: First birth after 30 years of age confers double the risk compared with first birth before 20 years of age (58). The protective effects of early birth and parity are less for breast cancer diagnosed before 40 years of age than for breast cancer diagnosed at older ages. Also, there is a transient increase in absolute risk after birth because of a mitogenic effect (59-61).

Breastfeeding: $4.3 \%$ reduction in relative risk per year of breast feeding (62).

Preneoplastic lesion: 1-2\% absolute risk per year; RR 2-10 depending on the type of lesion (63).

Modifiable

Diet and exercise: Healthy lifestyle including exercise and a balanced diet may reduce risk (64).

Overweight and obesity: Obesity may increase risk by about $20 \%(47,65-67)$. Weight gain after a breast cancer diagnosis confers an increase in all-cause mortality and breast-cancer-specific mortality (68-70). High body mass index could be protective for breast cancer in premenopausal women (71).

Smoking: Data on firsthand smoking and breast cancer are consistent with causality and data on secondhand smoking and breast cancer may be consistent with causality among young premenopausal women (72).

Alcohol: Regular consumption of alcohol may increase risk in premenopausal and postmenopausal women $(64,70)$. However, a recent German review did not find an increase in risk due to alcohol consumption (73).

Hormonal replacement therapy (HRT): One report showed a 5\% per year increase in RR in current users with RR returning to baseline within 1 year of discontinuation of HRT; patients who received HRT for more than 5 years significantly increased their risk (74). Another report showed an absolute $1-2 \%$ risk per year of therapy with risk returning to baseline within 5 years of discontinuation of HRT (75). Estrogen-only HRT has not been proven to increase risk (76).

Reproductive history: Recent studies suggest that reproductive and hormonal factors increase the risk mainly of estrogen-receptor-positive breast cancer subtypes (77).

Contraceptives: Data are contradictory. Some data show that current use of contraceptives does not confer a higher risk, even in BRCA mutation carriers, whereas other data show that current use of contraceptives increases risk of premenopausal breast cancer (78-85).

Vitamin D deficiency: The Institute of Medicine released a consensus statement on vitamin D concluding that there is not enough evidence to support a relationship between vitamin D and cancer risk (89). A recent meta-analysis supports this conclusion (86-89).

a Throughout the table, risk and RR refer to risk of breast cancer. 
It is important to assess an individual's risk as patients may overestimate their risk for developing breast cancer based on personal or familiar history, leading to erroneous decisions in screening and treatment $(93,94)$. A system to select the patients who require further evaluation should be created to optimize resources and acceptability (22).

Knowledge of risk factors will help clinicians develop risk levels and make clinical decisions. Risk factors that confer at least double the risk of average-risk women are considered major, and risk factors that confer less than double the risk of average-risk women are considered minor.

Definitions of "high risk" for breast cancer and definitions of breast cancer risk levels differ among medical societies. It may be appropriate to define risk differently for different populations and for countries with different resource levels. Such tailored risk definitions along with adoption of management guidelines created by local medical societies may result in the best approach for each program.

The American Cancer Society (95) defines high risk as a lifetime risk of $20 \%$ or more, moderate risk as a lifetime risk of $15-20 \%$, and normal risk as a lifetime risk of less than $15 \%$.

The NICE UK (96) risk definitions are as follows: low, 10-year risk of less than $3 \%$ for women aged 40-49 years or lifetime risk of less than $17 \%$; moderate, 10 -year risk of $3-8 \%$ for women aged $40-49$ years or lifetime risk of $17-29 \%$; and high, 10 year risk of more than $8 \%$ for women aged $40-49$ years or lifetime risk of greater than $30 \%$. Patients with a $20 \%$ or greater chance of carrying a BRCA1, BRCA2, or TP53 mutation are also classified as high risk.

In 2007, the International Consensus Conference on Breast Cancer Risk, Genetics, and Risk Management was held. The recommendations from that conference (45) are suitable for different practice settings because they suggest the use of locally tailored screening programs. The risk categories from the consensus conference are as follows:

- Average risk: Follow country-specific cancer screening recommendations. Hormonal replacement therapy (HRT) may be used in women with symptoms related to menopause for up to 5-10 years.

- Moderate risk: RR less than 5. Follow country-specific cancer screenings recommendations. Chemoprevention may be used. If HRT is needed, use the lowest dose for the shortest possible period of time.

- High risk: RR 5-10. Consider use of digital mammography. If lifetime risk is greater than $20 \%$, the use of magnetic resonance imaging (MRI) is suggested, and semiannual clinical breast examination is recommended. Consider use of chemoprevention. Risk reduction surgery is not usually indicated.

- Very high risk: RR greater than 10. Screen with annual MRI alternating at 6 months with mammography starting at age 25 years. Perform semiannual clinical examination and monthly breast self-examination. Chemoprevention must be discussed with patients. Risk reduction surgeries should be discussed.

\section{Evaluating Risk and Communicating Results}

If patients are to be expected to comply with recommended risk-reduction interventions, they need to understand their risk and the potential benefits from actions taken to reduce it. Unfortunately, there exists a situation, described by Gigerenzer et al. as "collective statistical illiteracy", in which many doctors, patients, journalists, and politicians are unable to understand health-related statistics and do not recognize that they are unable to understand them (97). Thus, great care must be taken to present risks in a manner that patients are most likely to understand.

As Vázquez Caruncho said in a very interesting paper, "When giving information to the patient, consider that the relative risks are not informative if they are not attached to their respective absolute risks. The most common error is to present the benefits of a strategy in terms of the reduction in the relative risk and the disadvantages or side effects in terms of the absolute risk. This leads to a misperception by exacerbating the benefits of an intervention and minimizing its complications" (translated from the original Spanish) (98).

The proposal of the aforementioned International Consensus Conference on Breast Cancer Risk, Genetics, and Risk Management is that risk should be expressed in absolute terms compared to the risk of an average woman in the patient's age group (45). Relative risks can be misleading and may not be well understood by patients and their families. For example, suppose a physician tells a patient that by taking tamoxifen she is likely to reduce her risk of breast cancer development by $50 \%$. For a patient with a BRCA mutation, the absolute lifetime risk of breast cancer could be as high as $60 \%$, and in such case the absolute risk reduction would be $30 \%$; however, a patient without any identifiable risk factors could have an absolute lifetime predicted risk as low as $8 \%$, and thus her absolute risk reduction would be only $4 \%$.

Another important issue is communication with colleagues who refer patients from other institutions, cities, or countries. Using consistent and clearly understandable terminology to communicate risk may 
help colleagues understand genetic testing results and proposed risk management strategies, which would allow those colleagues to make recommendations for follow-up and long-term management of high-risk patients without patients having to come to the multidisciplinary high-risk clinic all the time.

\section{Legal Issues and Confidentiality}

Legal issues must be addressed by every high-risk program. Depending on the country, there may be important issues related to the lack of laws about genetic syndromes and risk assessment. The information that is going to be generated must be managed confidentially; disclosure of such information to insurance companies and health care providers may be threatening for patients if there is no legislation that protects patients.

High-risk programs should obtain approval from patients and institutions to share very sensitive information and should create an information-sharing system that protects patient privacy (99). Such a system is particularly important in the case of referral or assessment of patients who live outside the city or country where the high-risk program is located.

\section{Risk Reduction Strategies for All Patients}

Regardless of their level of breast cancer risk, all patients should maintain a normal body mass index $(18.5-24.9 \mathrm{~kg} / \mathrm{m} 2)$, exercise regularly (at least 150 minutes per week of moderate-intensity activity or 75 minutes per week of vigorous activity), eat five servings of fruits and vegetables per day, and limit consumption of processed meat, red meat, refined grains, and alcohol (64).

Offering these recommendations to all patients is a simple and noninvasive primary prevention intervention that can have a huge positive impact on the population regardless of individuals' risk of breast cancer.

\section{Screening and Surveillance}

Mammography is the only screening strategy that has been proven to reduce mortality from breast cancer (100-102). The reported sensitivity of mammography in the detection of breast cancer ranges from $69 \%$ to $90 \%$, and the reported specificity ranges from $10 \%$ to $40 \%$ (103). Ultrasonography is not included in the National Comprehensive Cancer Network $(\mathrm{NCCN})$ breast cancer screening guidelines. However, ultrasonography may be useful to complement MRI or mammography.

The American College of Radiologists has stated that MRI is the ideal screening method for women with a lifetime breast cancer risk of $22-25 \%$ or greater. The NCCN guidelines suggest MRI alternating with mammography for patients with a lifetime risk of $20 \%$ or greater (100). MRI may detect $37 \%$ of breast cancers that were missed by mammography and clinical evaluation $(103,104)$.

The sensitivity of the combination of mammography, ultrasonography, and MRI in the detection of breast cancer is approximately $95 \%$; the sensitivity of mammography plus physical examination is $45 \%$ $(103,104)$. Currently, there is no evidence that MRI reduces breast cancer mortality, but MRI may lead to earlier diagnosis and thereby have an impact in terms of reducing mortality (105-110). The false-positive rate of MRI is controversial; the false-positive rate may be similar to that of mammography, but the rate is highly dependent on the experience of the radiology team (100,111-113). In major trials comparing MRI and mammography, the specificity of MRI is $81-97 \%$ and that of mammography is $93-100 \%(109,114-117)$.

There are interesting reports indicating that in the screening of very high risk patients, breast MRI alternating every 6 months with mammography leads to earlier diagnosis (118). With Monte Carlo models comparing combined screening with MRI and mammography versus prophylactic surgery in BRCA mutation carriers, the results in terms of overall survival were similar (119).

At Clinica Alemana, we suggest surveillance with breast MRI alternating with mammography and ultrasonography every 6 months in patients with at least a $20 \%$ lifetime risk of breast cancer. The frequency and types of images are as suggested by the NCCN guidelines.

\section{Prevention Therapy (Chemoprevention)}

Recently, it was proposed that the term chemoprevention be changed to preventive therapy to have better acceptability (120). Preventive therapy is defined as "the use of pharmacological or natural agents to inhibit the development of invasive cancer either by blocking the DNA damage that initiates the carcinogenesis or by arresting or reversing the progression of pre-malignant cells in which such damage has already occurred" (121). Preventive therapy may be applied to healthy people at high risk for development of a disease to prevent that disease, to patients with premalignant conditions to reduce the probability of development of invasive cancer, and to patients already treated for cancer to prevent a recurrence (122).

Drugs used in prevention should have benefits that outweigh by far the potential complications. The Food and Drug Administration has defined the group of patients eligible for breast cancer preventive therapy as those with a Gail model risk assessment of a greater than $1.66 \%$ risk of breast cancer development within 5 years. Breast cancer preventive therapies 
need a long period to show results. Adherence to treatment and pharmacological interactions may affect the results, and sadly, there is no test yet available to assure efficacy during treatment. This "uncertainty" about the benefits of preventive therapy, along with the potential side effects, may affect patient compliance with treatment.

The main drugs used for breast cancer chemoprevention are tamoxifen and raloxifene, both of which are selective estrogen receptor modulators. Tamoxifen reduces the probability of invasive breast cancer by $50 \%$, in situ cancer by $49 \%$, and atypical ductal hyperplasia by $89 \%$ (123).

A recent update of STAR trial, which compared tamoxifen to raloxifene for breast cancer prevention, showed that the raloxifene group had a $24 \%$ higher incidence of invasive breast cancer than the tamoxifen group. The prevention of in situ cancers was also worse with raloxifene, but the difference between tamoxifen and raloxifene in the prevention of in situ cancers was less than in the original report. However, raloxifene has a better safety profile than tamoxifen and might be suitable for some patients (124).

Approximately 2 million women are eligible for chemoprevention with tamoxifen in the United States, but only $4 \%$ of them accepted such treatment when it was offered. Subgroup analysis revealed that a minority of eligible women aged 40-79 years accepted use of tamoxifen (125-127).

Aromatase inhibitors have been shown to be effective in preventing breast cancer and to be less toxic than tamoxifen, in trials such as IBIS II (anastrozole 1 $\mathrm{mg} /$ day for 5 years versus placebo for postmenopausal women at high risk) and MAP 3 (exemestane $25 \mathrm{mg}$ / day for 5 years versus exemestane $25 \mathrm{mg}$ / day for 5 years plus celecoxib $200 \mathrm{mg} /$ day for 3 years versus placebo for postmenopausal women at high risk for breast cancer or diagnosed with ductal carcinoma in situ and treated with mastectomy). An estimated risk reduction of $65 \%$ has been designed to assess its efficacy in prevention. Final conclusions from the IBIS II study are pending.

The MAP 3 trial showed a $65 \%$ reduction in the risk of invasive breast cancer and also a reduction in the risk of in situ breast cancer among the exemestane users, and there were no significant differences in toxic effects and adverse effects between the treatment and placebo groups $(120,128-130)$.

Research on breast cancer risk reduction with other selective estrogen receptor modulators, aspirin, bisphosphonates, statins, nonsteroidal antiinflammatory drugs, and fenretinide seeks to aid patients with triple-negative breast cancer, for whom current options do not work, and uncover preventive strategies that could be offered after the usual 5 year duration of current preventive therapy (120).

Management guidelines such as the NCCN guidelines give information about patient eligibility for preventive therapy, recommended dosage, and recommended duration of use of preventive therapy (131).

At Clinica Alemana, we cannot follow the Food and Drug Administration's guideline of prescribing chemopreventive therapy to women with a greater than $1.66 \%$ risk of breast cancer development within 5 years because the Gail model was designed for a population different from our patient population. To determine whether to prescribe chemoprevention, we consider the pros and cons for each patient. Patient eligibility, dosage, and duration of use of preventive therapy are the main issues suggested by the NCCN and the Proceedings of the International Consensus Conference on Breast Cancer Risk, Genetics, and Risk Management $2007(45,131)$.

\section{Risk Reduction Surgery}

Risk reduction surgery, including bilateral risk reduction breast surgery and bilateral risk reduction salpingo-oophorectomy, may be performed in healthy people with a high risk of cancer development. Risk reduction surgery may also be performed in patients who have already been treated for or diagnosed with breast cancer, in which case the prophylactic procedure is done in the contralateral breast with or without salpingo-oophorectomy.

A study published in the Cochrane Database indicated that most women undergoing prophylactic mastectomies (bilateral and contralateral) will not experience a benefit in terms of overall survival, especially the ones choosing risk-reducing contralateral mastectomy (132). However, the data from that study regarding contralateral mastectomy for risk reduction have since been challenged by at least five publications that have shown a survival benefit from the procedure in selected groups of patients (133-137). Overall, all studies to date show a benefit in terms of reducing the risk of breast cancer development, but whether there is an overall survival benefit remains controversial (134). The rate of complications after contralateral prophylactic mastectomy and reconstruction is $15-20 \%$, and complications may delay adjuvant therapy $(138,139)$.

When informing a patient about her breast cancer risk before any decision is made about prophylactic surgery, it is important to keep in mind that the risk of development of breast cancer or contralateral breast cancer differs according to whether or not a BRCA mutation is present (139-146) (table 4). 
Table 4. Breast cancer risk and recurrence rates among BRCA mutation carriers and individuals without BRCA mutations.

\begin{tabular}{llll}
\hline Type of patient & $\begin{array}{l}\text { Probability of Breast Cancer over Probability of contralateral breast } \\
\text { lifetime }\end{array}$ & $\begin{array}{l}\text { Probability of synchronous } \\
\text { cancer }\end{array}$ & $\begin{array}{l}40 \% \text { within 10 years after initial } \\
\text { diagnosis of breast cancer }\end{array}$ \\
\hline BRCA mutation carriers & BRCA 1 mutation: 57-65\% & $(139,144)$ \\
& BRCA 2 mutation: 45-69\% \\
$(140-143)$ & $(140-143)$ & $\begin{array}{l}6 \% \text { within 10 years after initial } \\
\text { diagnosis of breast cancer (146) }\end{array}$ & $3-5 \%(139,14)$ \\
\hline
\end{tabular}

There was an impressive $150 \%$ increase in the number of patients undergoing contralateral prophylactic mastectomy in the United States between 1995 and 2005 (147-150). This is a worldwide trend, but fewer procedures per capita are performed in Europe than in the United States; ethnicity and cultural factors may influence decisions regarding prophylactic surgery (151-153). A Cochrane review of six observational studies concluded that contralateral prophylactic mastectomy reduces the risk of contralateral cancer but does not improve survival (132). This finding challenged the findings of several previously mentioned studies (133-137).

When advising a patient considering contralateral mastectomy after an initial diagnosis of breast cancer, it is important to keep in mind that she may substantially overestimate her risk of contralateral breast cancer and recurrence, which might influence her decision (154-157). The initial breast cancer is normally what determines overall survival; in most cases, metachronous contralateral breast cancers are detected at an early stage.

The number of women opting for bilateral prophylactic surgery is also increasing, but not as much as the number of women opting for contralateral prophylactic mastectomy (158). A reduction in risk of $90-95 \%$ has been reported for all types of patients undergoing bilateral prophylactic mastectomy, but the overall survival impact is not clear. Patients who choose this procedure still need follow-up and must understand that the risk reduction is not $100 \%$ (159). It is supposed that the majority of patients opting for bilateral prophylactic mastectomy will be BRCA mutation carriers because even under intensive surveillance, the incidence of contralateral invasive breast cancer development in BRCA mutation carriers is $33-40 \%(160,161)$.

Not only mutation carriers are having contralateral prophylactic surgeries, though, as indicated by a report by Stucky et al. showing a $20 \%$ increase in the number of patients undergoing this procedure between 2000 and 2008 in a population studied in Phoenix, Arizona, with only $0.79 \%$ of the patients be- ing diagnosed with a BRCA mutation (162).

There was also a $148 \%$ increase in the use of contralateral prophylactic surgery among patients with in situ cancers between 1998 and 2005, which does not seem to make sense considering the excellent overall survival in this group with standard treatments (163).

The Society of Surgical Oncology statement about breast risk reduction surgeries, which outlines potential indications and recommendations for these procedures, may aid in decision making about prophylactic surgery (164). Also, there is an online computerized model for comparing the benefits of risk reduction strategies in patients with BRCA mutations $(165,166)$.

Bilateral salpingo-oophorectomy reduces the risk of ovarian cancer (hazard ratio $[\mathrm{HR}]=0.21,95 \%$ CI, 0.12-0.39) and breast cancer (HR $=0.49,95 \% \mathrm{CI}$, 0.370 .65 ) and also may have an impact on overall survival if performed before 40 years of age. If bilateral mastectomy is performed at the same time as bilateral salpingo-ophorectomy, a 95\% reduction in breast cancer risk may be achieved (167-169).

With clear information, patients may choose among the different management strategies, considering the pros and cons of each alternative. This is a particularly difficult area in which the patient's preference may outweigh the medical criteria. Health care professionals should strive to ensure that whatever decisions patients ultimately make about risk reduction surgery, those decisions are informed decisions.

At Clinica Alemana, we evaluate in a standing multidisciplinary conference each patient for whom a prophylactic mastectomy is being considered. If the patient has not been diagnosed with cancer, the Society of Surgical Oncology recommendations are used as a guideline. If the patient has been diagnosed with breast cancer and is considering a contralateral prophylactic mastectomy, the decision whether or not to recommend the surgery is based on the index cancer prognosis, the patient's age, and the tumor hormone receptor status, and we clarify for the patient the benefits, limitations, and potential complications 
related to physical, psychological, and quality-of-life aspects.

\section{Final Thoughts}

Groups considering the implementation of a program for individuals at high risk for breast cancer should keep in mind that successful projects have common purposes and objectives. Performing a SWOT analysis may allow groups to capitalize on strengths and opportunities while being better prepared to overcome potential threats. In the creation of a high-risk program, groups may engage with people whose involvement may not necessarily be continuous or long term, like administrative staff of the institution or an external physician with experience in running a high-risk clinic. In Table 5, we have summarized the steps necessary to develop a multidisciplinary high-risk program. The recommendations in the table are based on the information gathered during the development of this paper. The risk assessment tools, patient data collection system, and risks levels are issues that need to be addressed by each new high-risk program.

Table 5. Proposed steps in the organization of a multidisciplinary program for individuals at high risk for breast cancer.

- Submit your idea to your institution and get their approval and support.

- Establish business relationships with health care insurance companies.

- Define the number of staff members needed for the program and the competences they require.

- Define the physical space and resources needed.

- Define short-term and long-term goals, define how will you monitor progress toward these goals and create measures to evaluate the project.

- At the beginning, base your referral criteria, screening strategies, and risk reduction strategies on validated international guidelines. With time, you will be able to develop local guidelines.

- Choose a risk assessment tool that is suitable for your population and useful in clinical practice. Probably a combination of two or more risk assessment tools is the better option.

- Define your different groups on the basis of previously described groups and if necessary, modify the definition of risk groups to fit the reality for your patient population

- Promote continuous education for the health care team and the community. Create committees or conferences open to referring physicians and other interested health care providers. PowerPoint presentations and written documents may be used for continuing medical education (CME) activities.

- Publish your results and compare them with results from other high-risk breast cancer programs.

- Try to develop a formal association with an established multidisciplinary program for individuals at high risk for breast cancer.

\section{Acknowledgement}

We thank Stephanie P. Deming of The University of Texas M. D. Anderson Cancer Center's Department of Scientific Publications for providing editorial assistance.

\section{Competing Interests}

The authors have declared that no competing interest exists.

\section{References}

1. [No authors listed]. Commission on Cancer: Cancer Program Standards. Revised Edition; Standard 6.1, p67. Chicago: American College of Surgeons. 2004.

2. Ferlay J, Shin HR, Bray F, et al. Estimates of worldwide burden of cancer in 2008: GLOBOCAN 2008. Int J Cancer 2010;127:2893-917.

3. [Internet] American Cancer Society. Breast cancer facts \& figures 2011-2012.

http://www.cancer.org/research/cancerfactsfigures/breastcancerfactsf igures/breast-cancer-facts-and-figures-2011-2012

4. Evans DG, Cuzick J, Howell A. Cancer genetics clinics. Eur J Cancer 1996;32A(3):391-2.

5. Althuis MD, Dozier JM, Anderson WF, et al. Global trends in breast cancer incidence and mortality 1973-1997. Int J Epidemiol 2005;34:405-12.

6. Parkin DM, Bray F, Ferlay J, et al. Global cancer statistics, 2002. CA Cancer J Clin 2005;55:74-108.

7. Tryggvadottir L, Sigvaldason H, Olafsdottir GH, et al. PopulationTbased study of changing breast cancer risk in Icelandic BRCA2 mutation carriers, 19202000. J Natl Cancer Inst 2006;98:116-22.

8. Evans DG, Shenton A, Woodward E, et al. Penetrance estimates for BRCA1 and BRCA2 based on genetic testing in a Clinical Cancer Genetics service setting: risks of breast/ovarian cancer quoted should reflect the cancer burden in the family. BMC Cancer 2008;8:155.

9. Powles TJ. Breast cancer prevention. Oncologist 2002;7:60-4.

10. Nelson HD, Huffman LH, Fu R, et al. U.S. Preventive Services Task Force. Genetic risk assessment and BRCA mutation testing for breast and ovarian cancer susceptibility: systematic evidence review for the U.S. Preventive Services Task Force. Ann Intern Med 2005;143:362-79.

11. [No authors listed]. American Society of Clinical Oncology policy statement update: genetic testing for cancer susceptibility. J Clin Oncol 2003;21:2397-406.

12. Daly MB, Axilbund JE, Bryant E, et al. Genetic/familial high-risk assessment: breast and ovarian. J Natl Compr Canc Netw 2006;4:156-76.

13. Weitzel JN. Evidence for advice: reduction in risk of breast or ovarian cancer after salpingo-oophorectomy in carriers of BRCA1 or BRCA2 mutations. Breast Dis 2004;14:354-6.

14. Weitzel JN. Genetic cancer risk assessment: putting it all together. Cancer 1999;86(suppl):2483-92.

15. Calzone KA, Stopfer J, Blackwood A, et al. Establishing a cancer risk evaluation program. Cancer Practice 1997;5:228-33.

16. Lewis CM, Cler LR, Bu DW, et al. Promoter hypermethylation in benign breast epithelium in relation to predicted breast cancer risk. Clin Cancer Res 2005;11:166-72.

17. Euhus DM, Bu DTW, Ashfaq R, et al. Atypia and DNA methylation in nipple duct lavage in relation to predicted breast cancer risk. Cancer Epidemiol Biomarkers Prev 2007;16:1812-21.

18. Euhus DM, Bu D, Milchgrub S, et al. DNA methylation in benign breast epithelium in relation to age and breast cancer risk. Cancer Epidemiol Biomarkers Prev 2008;17:1051-9.

19. Kwon JS, Gutierrez-Barrera AM, Young D, et al. Expanding the criteria for BRCA mutation testing in breast cancer survivors. J Clin Oncol 2010;28:4214-20.

20. MacDonald DJ. Establishing a cancer genetics service. In: Kuerer HM. Kuerer's Breast Surgical Oncology. New York: McGraw-Hill Medical; 2010.

21. Owens WL, Gallagher TJ, Kincheloe MJ, et al. Implementation in a large health system of a program to identify women at high risk for breast cancer. J Oncol Pract 2011; 7:85-8.

22. Palmero EI, Caleffi M, Schüler-Faccini L, et al. Population prevalence of hereditary breast cancer phenotypes and implementation of a genetic 
cancer risk assessment program in southern Brazil. Genet Mol Biol 2009;32:447-55.

23. Mulsow J, Lee J, Dempsey C, et al. Establishing a family risk assessment clinic for breast cancer. Breast J 2009;15 Suppl 1:S33-8.

24. MacDonald DJ, Sand S, Kass FC, et al. The power of partnership: extending comprehensive cancer center expertise in clinical cancer genetics to breast care in community centers. Semin Breast Dis 2006;9:39-47.

25. Ho C. How to develop and implement a cancer genetics risk assessment program: clinical and economic considerations. Oncology Issues 2004;19:226.

26. Banegas MP, Gail MH, LaCroix A, et al. Evaluating breast cancer risk projections for Hispanic women. Breast Cancer Res Treat 2012;132(1):347-53.

27. Amir E, Freedman OC, Seruga B, et al. Assessing women at high risk of breast cancer: a review of risk assessment models. J Natl Cancer Inst 2010;102:680-91.

28. Euhus D. Quantitative risk prediction. In: Kuerer HM. Kuerer's Breast Surgical Oncology. New York: McGraw-Hill Medical; 2010.

29. De la Hoya M, Díez O, PérezTSegura P, et al. Pre-test prediction models of BRCA1 or BRCA2 mutation in breast/ovarian families attending familial cancer clinics. J Med Genet 2003;40(7):503-10.

30. Costantino JP, Gail MH, Pee D, et al. Validation studies for models projecting the risk of invasive and total breast cancer incidence. J Natl Cancer Inst 1999;91:1541-8.

31. Rockhill B, Spiegelman D, Byrne C, et al. Validation of the Gail et al. model of breast cancer risk prediction and implications for chemoprevention. J Natl Cancer Inst 2001;93:358-66.

32. Pankratz VS, Hartmann LC, Degnim AC, et al. Assessment of the accuracy of the Gail model in women with atypical hyperplasia. J Clin Oncol 2008;33:5374-9.

33. Barlow WE, White E, Ballard-Barbash R, et al. Prospective breast cancer risk prediction model for women undergoing screening mammography. J Natl Cancer Inst 2006;98:1204-14.

34. Parmigiani G, Chen S, Iversen ESJ, et al. Validity of models for predicting BRCA1 and BRCA2 mutations. Ann Intern Med 2007;147:441-50.

35. James PA, Doherty R, Harris M, et al. Optimal selection of individuals for BRCA mutation testing: a comparison of available methods. J Clin Oncol 2006;24:707-15

36. Antoniou AC, Easton DF. Risk prediction models for familial breast cancer. Future Oncol 2006;2(2):257-74.

37. Shannon KM, Lubratovich ML, Finkelstein DM, et al. Model-based predictions of BRCA1/2 mutation status in breast carcinoma patients treated at an academic medical center. Cancer 2002;94(2):305-13.

38. Berry DA, Iversen ES Jr, Gudbjartsson DF, et al. BRCAPRO validation, sensitivity of genetic testing of BRCA1/BRCA2, and prevalence of other breast cancer susceptibility genes. J Clin Oncol 2002;20(11):2701-12.

39. Euhus DM, Smith KC, Robinson L, et al. Pretest prediction of BRCA1 or BRCA2 mutation by risk counselors and the computer model BRCAPRO. J Natl Cancer Inst 2002;94(11):844-51.

40. Barcenas CH, Hosain GM, Arun B, et al. Assessing BRCA carrier probabilities in extended families. J Clin Oncol 2006;24(3):354-60.

41. Kang HH, Williams R, Leary J, et al. Evaluation of models to predict BRCA germline mutations. Br J Cancer 2006;95(7):914-20.

42. Simard J, Dumont M, Moisan AM, et al. Evaluation of BRCA1 and BRCA2 mutation prevalence, risk prediction models and a multistep testing approach in French-Canadian families with high risk of breast and ovarian cancer. J Med Genet 2007;44(2):107-21.

43. Antoniou AC, Hardy R, Walker L, et al. Predicting the likelihood of carrying a BRCA1 or BRCA2 mutation: validation of BOADICEA, BRCAPRO, IBIS, Myriad and the Manchester scoring system using data from UK genetics clinics. J Med Genet 2008;45(7):425-31.

44. McIntosh A, Shaw C, Evans G, et al. Clinical Guidelines and Evidence Review for the Classification and Care of Women at Risk of Familial Breast Cancer. NICE Guideline CG014. London, UK: National Collaborating Centre for Primary Care/University of Sheffield; 2006.

45. Schwartz GF, Hughes KS, Lynch HT, et al. Proceedings of the International Consensus Conference on Breast Cancer Risk, Genetics, \& Risk Management, April, 2007. Breast J 2009;15:4-16.

46. Struewing JP, Hartge P, Wacholder $S$, et al. The risk of cancer associated with specific mutations of BRCA1 and BRCA2 among Ashkenazi Jews. N Engl J Med 1997;336(20):1401-8.

47. Roa BB, Boyd AA, Volcik K, et al. Ashkenazi Jewish population frequencies for common mutations in BRCA1 and BRCA2. Nat Genet 1996;14(2):185-7.

48. Neuhausen S, Gilewski T, Norton L, et al. Recurrent BRCA2 6174delT mutations in Ashkenazi Jewish women affected by breast cancer. Nat Genet 1996;13(1):126-8.
49. Peelen T, van Vliet M, Petrij-Bosch A, et al. A high proportion of novel mutations in BRCA1 with strong founder effects among Dutch and Belgian hereditary breast and ovarian cancer families. Am J Hum Genet 1997;60(5):1041-9.

50. Thorlacius S, Olafsdottir G, Tryggvadottir L, et al. A single BRCA2 mutation in male and female breast cancer families from Iceland with varied cancer phenotypes. Nat Genet 1996;13(1):117-9.

51. Arason A, Jonasdottir A, Barkardottir RB, et al. A population study of mutations and $\mathrm{LOH}$ at breast cancer gene loci in tumours from sister pairs: two recurrent mutations seem to account for all BRCA1/BRCA2 linked breast cancer in Iceland. J Med Genet 1998;35(6):446-9.

52. Einbeigi Z, Bergman A, Kindblom LG, et al. A founder mutation of the BRCA1 gene in Western Sweden associated with a high incidence of breast and ovarian cancer. Eur J Cancer 2001;37(15):1904-9.

53. Collaborative Group on Hormonal Factors in Breast Cancer. Familial breast cancer: collaborative reanalysis of individual data from 52 epidemiological studies including 58,209 women with breast cancer and 101,986 women without the disease. Lancet 2001;358(9291):1389-99.

54. Travis LB, Hill D, Dores GM, et al. Cumulative absolute breast cancer risk for young women treated for Hodgkin lymphoma. J Natl Cancer Inst 2005;97:1428-37.

55. Jonker MA, Jacobi CE, Hoogendoorn WE, et al. Modeling familial clustered breast cancer using published data. Cancer Epidemiol Biomarkers Prev 2003;12(12):1479-85.

56. Singletary SE. Rating the risk factors for breast cancer. Ann Surg 2003;237:474-82.

57. Chen Y, Thompson W, Semenciw R, et al. Epidemiology of contralateral breast cancer. Cancer Epidemiol Biomarkers Prev 1999; 8:855.

58. Antoniou AC, Shenton A, Maher ER, et al. Parity and breast cancer risk among BRCA1 and BRCA2 mutation carriers. Breast Cancer Res 2006;8(6):R72.

59. Clavel-Chapelon F, Gerber M. Reproductive factors and breast cancer risk. Do they differ according to age at diagnosis? Breast Cancer Res Treat 2002;72:107-15.

60. Liu Q, Wuu J, Lambe M, et al. Transient increase in breast cancer risk after giving birth: postpartum period with the highest risk (Sweden). Cancer Causes Control 2002;13:299-305.

61. Lyons TR, Schedin PJ, Borges VF. Pregnancy and breast cancer: when they collide. J Mammary Gland Biol Neoplasia 2009;14:87-98.

62. Collaborative Group on Hormonal Factors in Breast Cancer. Breast cancer and breastfeeding: collaborative reanalysis of individual data from 47 epidemiological studies in 30 countries, including 50302 women with breast cancer and 96973 women without the disease. Lancet 2002;360(9328):187-195

63. Dupont WD, Parl FF, Hartmann WH, et al. Breast cancer risk associated with proliferative breast disease and atypical hyperplasia. Cancer 1993;71(4):1258-65.

64. McCullough ML, Patel AV, Kushi LH, et al. Following cancer prevention guidelines reduces risk of cancer, cardiovascular disease, and all-cause mortality. Cancer Epidemiol Biomarkers Prev 2011;20(6):1089-97.

65. Chlebowski RT, Blackburn GL, Thomson CA, et al. Dietary fat reduction and breast cancer outcome: interim efficacy results from the Women's Intervention Nutrition Study. J Natl Cancer Inst 2006;98(24):1767-76.

66. Begum P, Richardson CE, Carmichael AR. Obesity in post menopausal women with a family history of breast cancer: prevalence and risk awareness. Int Semin Surg Oncol 2009;6:1.

67. Caan BJ, Aragaki A, Thomson CA, et al. Vasomotor symptoms, adoption of a low fat dietary pattern, and risk of invasive breast cancer: a secondary analysis of the Women's Health Initiative randomized controlled dietary modification trial. J Clin Oncol 2009;27:4500-7.

68. Protani M, Coory M, Martin JH. Effect of obesity on survival of women with breast cancer: systematic review and meta-analysis. Breast Cancer Res Treat 2010;123: 627-35.

69. Chlebowski RT, Aiello E, McTiernan A. Weight loss in breast cancer patient management. J Clin Oncol 2002; 20:1128-43.

70. World Cancer Research Fund and American Institute for Cancer Research. Food, Nutrition, Physical Activity, and the Prevention of Cancer: a Global Perspective. Washington DC: AICR; 2007.

71. Carmichael AR, Bates T. Obesity and breast cancer: a review of the literature. Breast 2004;13:85-92.

72. Johnson $\mathrm{KC}$, Miller $\mathrm{AB}$, Collishaw $\mathrm{NE}$, et al. Active smoking and secondhand smoke increase breast cancer risk: the report of the Canadian Expert Panel on Tobacco Smoke and Breast Cancer Risk (2009). Tob Control 2011;20(1):e2

73. Hauner D, Janni W, Rack B, et al. The effect of overweight and nutrition on prognosis in breast cancer. Dtsch Arztebl Int 2011;108(47):795-801. 
74. Beral V, Million Women Study Collaborators. Breast cancer and hormoneT replacement therapy in the Million Women Study. Lancet 2003;362(9382):419-27.

75. Collaborative Group on Hormonal Factors in Breast Cancer. Breast cancer and hormone replacement therapy: collaborative reanalysis of data from 51 epidemiological studies of 52,705 women with breast cancer and 108,411 women without breast cancer. Lancet 1997;350(9084):1047-59.

76. Writing Group for the Women's Health Initiative Investigators. Risks and benefits of estrogen plus progestin in healthy postmenopausal women. JAMA 2002;288(3):321-33.

77. Goss PE, Ingle JN, Ales-Martinez JE, et al. Exemestane for breast-cancer prevention in postmenopausal women. N Engl J Med 2011;364:2381-91.

78. Jernström H, Loman N, Johannsson OT, et al. Impact of teenage oral contraceptive use in a population-based series of early-onset breast cancer cases who have undergone BRCA mutation testing. Eur J Cancer 2005;41(15): 2312-20.

79. Narod SA, Dubé MP, Klijn J, et al. Oral contraceptives and the risk of breast cancer in BRCA1 and BRCA2 mutation carriers. J Natl Cancer Inst 2002;94(23):1773-9.

80. Collaborative Group on Hormonal Factors in Breast Cancer. Breast cancer and hormonal contraceptives: collaborative reanalysis of individual data on 53297 women with breast cancer and 100239 women without breast cancer from 54 epidemiological studies. Lancet 1996;347(9017):1713-27.

81. Ursin G, Henderson BE, Haile RW, et al. Does oral contraceptive use increase the risk of breast cancer in women with BRCA1/BRCA2 mutations more than in other women? Cancer Res 1997;57(17):3678-81.

82. Iodice $S$, Barile $\mathrm{M}$, Rotmensz N, et al. Oral contraceptive use and breast or ovarian cancer risk in BRCA1/2 carriers: a meta-analysis. Eur J Cancer 2010;46(12):2275-84.

83. Brohet RM, Goldgar DE, Easton DF, et al. Oral contraceptives and breast cancer risk in the international BRCA1/2 carrier cohort study: a report from EMBRACE, GENEPSO, GEOTHEBON, and the IBCCS Collaborating Group. J Clin Oncol 2007;25(25):3831-6.

84. Haile RW, Thomas DC, McGuire V, et al. BRCA1 and BRCA2 mutation carriers, oral contraceptive use, and breast cancer before age 50. Cancer Epidemiol Biomarkers Prev 2006;15(10):1863-70.

85. Althuis MD, Brogan DD, Coates RJ, et al. Breast cancer among very young premenopausal women. Cancer Causes Control 2003;14:151-60.

86. Ross AC, Taylor CL, Yaktine AL, et al. Dietary Reference Intakes for Calcium and Vitamin D. Washington, DC: National Academies Press; 2011.

87. Pirianov G, Colston KW. Interaction of vitamin D analogs with signaling pathways leading to active cell death in breast cancer cells. Steroids 2001;66(3-5):309-18.

88. Colston KW, Berger U, Coombes RC. Possible role for vitamin D in controlling breast cancer cell proliferation. Lancet 1989;1(8631):188-91.

89. Chung M, Lee J, Terasawa T, et al. Vitamin D with or without calcium supplementation for prevention of cancer and fractures: an updated meta-analysis for the U.S. Preventive Services Task Force. Ann Intern Med 2011;155:827-38

90. Blackwood MA, Weber BL. BRCA1 and BRCA2: from molecular genetics to clinical medicine. J Clin Oncol 1998;16:1969-77.

91. Jemal A, Siegel R, Ward E, et al. Cancer statistics, 2008. CA Cancer J Clin 2008:58:71-96.

92. Madigan MP, Ziegler RG, Benichou J, et al. Proportion of breast cancer cases in the United States explained by well-established risk factors. J Natl Cancer Inst 1995;87:1681-5.

93. Haas JS, Kaplan CP, Des Jarlais G, et al. Perceived risk of breast cancer among women at average and increased risk. J Women's Health 2005;14:845-51.

94. Mikkelsen EM, Sunde L, Johansen C, et al. Risk perception among women receiving genetic counseling: a population-based follow-up study. Cancer Detect Prev 2007;31:457-64.

95. [Internet] http://www.cancer.org/cancer/breastcancer/moreinformation/breast cancerearlydetection/ breast-cancer-early-detection-acs-recs.

96. [Internet] http:/ / publications.nice.org.uk/familial-breast-cancer-cg41/guidance\# risklevels- and-estimates-presented-in-this-guideline.

97. Gigerenzer G, Gaissmaier W, KurzTMilcke E, et al. Helping doctors and patients to make sense of health statistics. Psychol Sci Public Interest 2007;8(2):53-96

98. Vázquez Caruncho M. Mujeres con alta probabilidad de padecer cáncer de mama. Luces, sombras y muchos puntos oscuros. Radiología. 2012;54(5):462-4.
99. Ready K, Arun BK, Schmeler KM, et al. Communication of BRCA1 and BRCA2 genetic test results to health care providers following genetic testing at a tertiary care center. Fam Cancer 2011;10:673-9.

100. [Internet] [No authors listed]. ACR practice guideline for the performance of contrast-enhanced magnetic resonance imaging (MRI) of the breast.

http://www.acr.org/ / media/ACR/Documents/PGTS/guidelines/M RI Breast.pd f.

101. Reddy DH, Mendelson EB. Incorporating new imaging models in breast cancer management. Curr Treat Options Oncol 2005;6(2):135-45.

102. Prasad SN, Houserkova D. The role of various modalities in breast imaging. Biomed Pap Med Fac Univ Palacky Olomouc Czech Repub 2007;151(2):209-18

103. Shah SK, Greatrex K. Current role of magnetic resonance imaging in breast imaging: a primer for the primary care physician. J Am Board Fam Pract 2005;18(6):478-90.

104. Odle T. Breast MR. Radiol Tech 2006;78(1):45M-66M.

105. Lord SJ, Lei W, Craft P, et al. A systematic review of the effectiveness of magnetic resonance imaging (MRI) as an addition to mammography and ultrasound in screening young women at high risk of breast cancer. Eur J Cancer 2007;43(13):1905-17.

106. Ojeda-Fournier H, Comstock CE. MRI for breast cancer: current indications. Indian J Radiol Imaging 2009;19(2):161-9.

107. Lehman CD, Blume JD, Weatherall P, et al. Screening women at high risk for breast cancer with mammography and magnetic resonance imaging. Cancer 2005;103(9):1898-1905.

108. Lee JM, Kopans DB, McMahon PM, et al. Breast cancer screening in BRCA1 mutation carriers: effectiveness of MR imaging-Markov Monte Carlo decision analysis. Radiology 2008;246(3):763-71.

109. Warner E, Plewes D, Hill KA, et al. Surveillance of BRCA1 and BRCA2 mutation carriers with magnetic resonance imaging, ultrasound, mammography, and clinical breast examination. JAMA 2004;292(11):1317-25.

110. Uematsu T, Yuen S, Kasami M, et al. Dynamic contrast-enhanced MR imaging in screening detected microcalcification lesions of the breast: is there any value? Breast Cancer Res Treat 2007;103(3):269-81.

111. Moore SG, Shenoy PJ, Fanucchi L, et al. Cost-effectiveness of MRI compared to mammography for breast cancer screening in a high risk population. BMC Health Serv Res 2009;9:9.

112. Le-Petross $\mathrm{CH}$, Bidaut L, Yang WT. Evolving role of imaging modalities in inflammatory breast cancer. Semin Oncol 2008;35(1):51-63.

113. Abramovici G, Mainiero MB. Screening breast MR imaging: comparison of interpretation of baseline and annual follow-up studies. Radiology 2011;259(1):85-91.

114. Kriege M, Brekelmans CTM, Boetes C, et al. Efficacy of MRI and mammography for breast-cancer screening in women with a familial or genetic predisposition. N Engl J Med 2004;351:427-37.

115. Leach MO, Boggis CRM, Dixon AK, et al. Screening with magnetic resonance imaging and mammography of a UK population at high familial risk of breast cancer: a prospective multicentre cohort study (MARIBS). Lancet 2005;365:1769-78.

116. Kuhl CK, Schrading S, Leutner CC, et al. Mammography, breast ultrasound, and magnetic resonance imaging for surveillance of women at high familial risk for breast cancer. J Clin Oncol 2005;23:8469-76.

117. Riedl CC, Ponhold L, Folry D, et al. Magnetic resonance imaging of the breast improves detection of invasive cancer, preinvasive cancer and premalignant lesions during surveillance of women at high risk for breast cancer. Clin Cancer Res 2007;13:6144-52.

118. Le-Petross HT, Whitman GJ, Atchley DP, et al. Effectiveness of alternating mammography and magnetic resonance imaging for screening women with deleterious BRCA mutations at high risk of breast cancer. Cancer 2011;177(17):3900-7.

119. Kurian AW, Sigal BM, Plevritis SK. Survival analysis of cancer risk reduction strategies for BRCA1/2 mutation carriers. J Clin Oncol 2010;28:222-31.

120. Cuzick J, DeCensi A, Arun B, et al. Preventive therapy for breast cancer: a consensus statement. Lancet Oncol 2011;12:496-503.

121. Hong WK, Sporn MB. Recent advances in chemoprevention of cancer. Science 1997;278:1073-7.

122. Bozovic-Spasojevic I, Azambuja E, McCaskill-Stevens W, et al. Chemoprevention for breast cancer. Cancer Treat Rev 2011;38(5):329-39.

123. Fisher B, Costantino JP, Wickerham DL, et al. Tamoxifen for prevention of breast cancer: report of the National Surgical Adjuvant Breast and Bowel Project PT1 Study. J Natl Cancer Inst 1998;90:1371-88.

124. Vogel VG, Costantino JP, Wickerham DL, et al. Update of the National Surgical Adjuvant Breast and Bowel Project Study of Tamoxifen and Raloxifene (STAR) PT2 Trial: preventing breast cancer. Cancer Prev Res (Phila) 2010;3:696-706. 
125. Visvanathan K, Chlebowski RT, Hurley P, et al. American Society of Clinical Oncology 2008 clinical practice guideline update on the use of pharmacologic interventions including tamoxifen, raloxifene, and aromatase inhibition for breast cancer risk reduction. J Clin Oncol 2009;27:3235-58.

126. Waters WA, Cronin KA, Graubard BI, et al. Prevalence of tamoxifen use for breast cancer chemoprevention among U.S. women. Cancer Epidemiol Biomarkers Prev 2010;19:443-6.

127. Ropka ME, Keim J, Philbrick JT. Patient decisions about breast cancer chemoprevention: a systematic review and meta-analysis. J Clin Oncol 2010;28:3090-5.

128. Cuzick J. Aromatase inhibitors for breast cancer prevention. J Clin Oncol 2005;23:1636-43.

129. Richardson H, Johnston D, Pater J, et al. The National Cancer Institute of Canada Clinical Trials Group MAP.3 trial: an international breast cancer prevention trial. Curr Oncol 2007;14:89-96.

130. Goss PE, Ingle JN, AlésTMartínez JE, et al. Exemestane for breast-cancer prevention in postmenopausal women. $N$ Engl J Med 2011;364(25):2381-91.

131. [Internet] NCCN clinical practice guidelines in oncology. Breast cancer . http://www.nccn.org/professionals/physician_gls/pdf/breast.pdf. Accessed march 212013

132. Lostumbo L, Carbine NE, Wallace J. Prophylactic mastectomy for the prevention of breast cancer. Cochrane Database Syst Rev 2010;11:CD002748.

133. Peralta EA, Ellenhorn JD, Wagman LD, et al. Contralateral prophylactic mastectomy improves the outcome of selected patients undergoing mastectomy for breast cancer. Am J Surg 2000;180:439-45.

134. Herrinton LJ, Barlow WE, Yu O, et al. Efficacy of prophylactic mastectomy in women with unilateral breast cancer: a cancer research network project. J Clin Oncol 2005;23:4275-86.

135. Bedrosian I, Hu CY, Chang GJ. Population-based study of contralateral prophylactic mastectomy and survival outcomes of breast cancer patients. J Natl Cancer Inst 2010;102:401-9.

136. Boughey JC, Hoskin TL, Degnim AC, et al. Contralateral prophylactic mastectomy is associated with a survival advantage in high-risk women with a personal history of breast cancer. Ann Surg Oncol 2010;17(10):2702-9.

137. Brewster AM, Bedrosian I, Parker PA, et al. Association between contralateral prophylactic mastectomy and breast cancer outcomes by hormone receptor status. Cancer 2012;118(22):5637-43.

138. Woerdeman LA, Hage JJ, Smeulders MJ, et al. Skin-sparing mastectomy and immediate breast reconstruction by use of implants: an assessment of risk factors for complications and cancer control in 120 patients. Plast Reconstr Surg 2006;118:321-30.

139. Goldflam K, Hunt KK, Gershenwald JE, et al. Contralateral prophylactic mastectomy. Predictors of significant histologic findings. Cancer 2004;101:1977-86.

140. Metcalfe K, Lynch HT, Ghadirian P, et al. Contralateral breast cancer in BRCA1 and BRCA2 mutation carriers. J Clin Oncol 2004;22:2328 -35.

141. Easton DF, Ford D, Bishop DT. Breast and ovarian cancer incidence in BRCA1Tmutation carriers. Breast Cancer Linkage Consortium. Am J Hum Genet 1995;56:265-71.

142. Antoniou A, Pharoah PD, Narod S, et al. Average risks of breast and ovarian cancer associated with BRCA1 or BRCA2 mutations detected in case series unselected for family history: a combined analysis of 22 studies. Am J Hum Genet 2003; 72(5):1117-30.

143. Chen S, Parmigiani G. Meta-analysis of BRCA1 and BRCA2 penetrance. J Clin Oncol 2007; 25(11):1329-33.

144. Lehman CD, Gatsonis C, Kuhl CK, et al. MRI evaluation of the contralateral breast in women with recently diagnosed breast cancer. $\mathrm{N}$ Engl J Med 2007;356:1295-303.

145. Altekruse SF, Kosary CL, Krapcho M, et al. SEER Cancer Statistics Review, 1975-2007. Bethesda, MD: National Cancer Institute, 2010.

146. Gao X, Fisher SG, Emami B. Risk of second primary cancer in the contralateral breast in women treated for early-stage breast cancer: a population-based study. Int J Radiat Oncol Biol Phys 2003;56:1038-45.

147. Tuttle TM, Habermann EB, Grund EH, et al. Increasing use of contralateral prophylactic mastectomy for breast cancer patients: a trend toward more aggressive surgical treatment. J Clin Oncol 2007;25:5203-9.

148. McLaughlin CC, Lillquist PP, Edge SB. Surveillance of prophylactic mastectomy: trends in use from 1995 through 2005. Cancer 2009;115:540412.

149. Recht A. Contralateral prophylactic mastectomy: caveat emptor. J Clin Oncol 2009;27:1347-9.

150. Bayraktar S, Elsayegh N, Gutierrez Barrera A, et al. Predictive factors for BRCA $1 / 2$ mutations in women with DCIS. Cancer 2012;118(6):1515-22.
151. Arrington AK, Jarosek SL, Virnig BA, et al. Patient and surgeon characteristics associated with increased use of contralateral prophylactic mastectomy in patients with breast cancer. Ann Surg Oncol 2009;16:2697-704

152. Jones NB, Wilson J, Kotur L, et al. Contralateral prophylactic mastectomy for unilateral breast cancer: an increasing trend at a single institution. Ann Surg Oncol 2009;16:2691-6.

153. Lerman C, Narod S, Schulman K, et al. BRCA1 testing in families with hereditary breast-ovarian cancer: a prospective study of patient decision making and outcomes. JAMA 1996;275(24): 1885-92.

154. Black WC, Nease RF Jr, Tosteson AN. Perceptions of breast cancer risk and screening effectiveness in women younger than 50 years of age. J Natl Cancer Inst 1995;87:720-31.

155. Alexander NE, Ross J, Sumner W, et al. The effect of an educational intervention on the perceived risk of breast cancer. J Gen Intern Med 1996;11:92-7.

156. Partridge A, Adloff K, Blood E, et al. Risk perceptions and psychosocial outcomes of women with ductal carcinoma in situ: longitudinal results from a cohort study. J Natl Cancer Inst 2008;100:243-51.

157. Rakovitch E, Franssen E, Kim J, et al. A comparison of risk perception and psychological morbidity in women with ductal carcinoma in situ and early invasive breast cancer. Breast Cancer Res Treat 2003;77:285-93.

158. McLaughlin CC, Lillquist PP, Edge SB. Surveillance of prophylactic mastectomy. Cancer 2009;115:5404-12.

159. Zakaria S, Degnim AC. Prophylactic mastectomy. Surg Clin North Am 2007;87:317-31.

160. Brekelmans CT, Seynaeve C, Bartels CC, et al. Effectiveness of breast cancer surveillance in BRCA1/2 gene mutation carriers and women with high familial risk. J Clin Oncol 2001;19(4):924-30.

161. Scheuer L, Kauff N, Robson M, et al. Outcome of preventive surgery and screening for breast and ovarian cancer in BRCA mutation carriers. J Clin Oncol 2002;20(5):1260-8.

162. Stucky CC, Gray RJ, Wasif N, et al. Increase in contralateral prophylactic mastectomy: echoes of a bygone era? Surgical trends for unilateral breast cancer. Ann Surg Oncol 2010;17(suppl 3):330 -7.

163. Tuttle TM, Jarosek S, Habermann EB, et al. Increasing rates of contralateral prophylactic mastectomy among patients with ductal carcinoma in situ. J Clin Oncol 2009;27(9):1362-7.

164. Giuliano AE, Boolbol S, Degnim A, et al. Society of Surgical Oncology: position statement on prophylactic mastectomy. Approved by the Society of Surgical Oncology Executive Council, March 2007. Ann Surg Oncol 2007;14:2425-7.

165. Kurian AW, Munoz DF, Rust $P$, et al. Online tool to guide decisions for BRCA1/2 mutation carriers. J Clin Oncol 2012;30:497-506.

166. Sigal BM, Munoz DF, Kurian AW, et al. A simulation model to predict the impact of prophylactic surgery and screening on the life expectancy of BRCA1 and BRCA2 mutation carriers. Cancer Epidemiol Biomarkers Prev 2012;21(7):1066-77.

167. Cass I, Baldwin RL, Varkey T, et al. Improved survival in women with BRCAT associated ovarian carcinoma. Cancer 2003;97(9):2187-95.

168. Aida $\mathrm{H}$, Takakuwa $\mathrm{K}$, Nagata $\mathrm{H}$, et al. Clinical features of ovarian cancer in Japanese women with germTline mutations of BRCA1. Clin Cancer Res 1998;4(1):235-40.

169. Kauff ND, Domchek SM, Friebel TM, et al. Risk-reducing salpingo-oophorectomy for the prevention of BRCA1 and BRCA2 associated breast and gynecologic cancer: a multicenter, prospective study. J Clin Oncol 2008;26(8):1331-7. 